\title{
Attitudes and perceived barriers to women participating in a proposed community-based conservation programme in Belize
}

\author{
Amanda S. Kaeser, Adam S. Willcox and Nidia C. Panti
}

\begin{abstract}
Many global efforts to decrease deforestation have focused on community-based conservation programmes to reach their goals. However, many such programmes are lacking a potentially helpful population, women. We employed key-informant interviews to examine attitudes towards, and barriers to, women's participation in a community-based conservation programme prior to implementation. We conducted 47 semi-structured interviews in January 2015 in communities adjacent to the Vaca Forest Reserve in the Cayo District of Belize. Results indicated that the benefits of involving women in community-based conservation activities included them learning more about the forest and conservation, transferring this knowledge to their family and community, and helping the environment. Some possible barriers to participation included lack of time and motivation to participate. However, there were notable differences between men's and women's responses relating to women's available time and their willingness to participate, with men not mentioning time as a barrier and stating that women would need more motivation to participate. The results will be used to work with local women to collaboratively develop and implement a community-based conservation programme around the Vaca Forest Reserve.
\end{abstract}

Keywords Belize, community-based conservation, elicitation study, theory of planned behaviour, Vaca Forest Reserve, women's participation

To view supplementary material for this article, please visit https://doi.org/10.1017/So030605316000715

\section{Introduction}

Cince the 1980 os many global conservation efforts have $\checkmark$ moved to more community-based approaches to reach their goals (Barrett et al., 2001; Berkes, 2004; Roe, 2008). According to Brown (2002), 'experience has shown that traditional, top-down exclusionary approaches to protected

\footnotetext{
Amanda S. Kaeser (Corresponding author) and AdAm S. Willcox Department of Forestry, Wildlife and Fisheries, University of Tennessee, Knoxville, Tennessee, USA. E-mail Aricha20@vols.utk.edu

Nidia C. PANTi Department of Natural Science, University of Belize, Belmopan, Cayo, Belize

Received 12 January 2016. Revision requested 21 March 2016.

Accepted 23 June 2016. First published online 28 October 2016.
}

areas are often not effective in reaching conservation objectives.' Programmes designed to include communities in conservation efforts, referred to as community-based conservation, have been successful (Hartup, 1994; PorterBolland et al., 2012; Thompson, 2013). By involving local communities in the sustainable management and conservation of the natural resources on which they rely, illegal deforestation and other degrading practices may decrease, as local people have vested interests in forest resources remaining abundant. This dependent relationship between local livelihoods and natural resources should provide an incentive for conservation (Brown, 2002; Belcher \& Schreckenberg, 2007). A meta-analysis indicated that many communitybased conservation programmes in tropical forests have reduced deforestation rates compared to governmentmanaged areas, and this has been attributed to locally relevant, culturally appropriate, and enforceable regulations being set by local communities rather than the government (Porter-Bolland et al., 2012). Community-based conservation programmes have also been shown to strengthen local governments, empower the poor and reduce local conflicts through better cooperation and compliance with regulations (Thompson, 2013). By emphasizing community involvement and combining conservation efforts with economic development, conservation practitioners can enhance nature and improve local communities (Getz et al., 1999; Berkes, 2004). However, many of these programmes lack participation by women, a key group that, if included, can lead to greater success (Agarwal, 2000, 2001, 2009; Prasad Timsina, 2003; Westermann et al., 2005).

Studies of community-based conservation programmes have reported lesser involvement of women compared to men, but that programmes involving women have better outcomes than those that do not (Agarwal, 2000, 2001, 2009; Soe \& Sato, 2012). Groups with more women tend to have better collaboration, solidarity and conflict resolution, because 'women tend to build more relational social capital than men' (Westermann et al., 2005). Community forest groups with more women showed greater improvement in forest conditions on all indicators, with a $57 \%$ higher probability of improvement when the groups included two or more women (Agarwal, 2009). This was attributed to greater compliance with rules, women's knowledge of plant species, more sustainable methods of resource harvesting, and greater cooperation. Women were also found to have strong feelings of forest ownership and continued to 
monitor illegal activity while performing their daily work (Agarwal, 2009). Because of the potential benefits of involving women, managers and organizations developing conservation programmes are encouraged to include women in their design and implementation.

Community-based conservation programmes around the globe have been implemented with and without women's participation (Agarwal, 2000). However, few attitudinal and behavioural studies have been conducted prior to initiating such programmes. We believe this is a necessary step for the success of a community-based conservation programme. We argue that some barriers and failures can be anticipated and overcome by conducting an initial behavioural analysis of a potential programme. Our main objective was to determine the attitudes and perceptions of local community members and other stakeholders regarding the creation of a community-based conservation programme for women. Understanding the attitudes and potential barriers to participation before a programme is created will help us design a programme that maximizes participant numbers and better ensures its success.

\section{Theoretical framework}

The theory of planned behaviour is a commonly used model to predict behavioural intent. First proposed by Ajzen in 1985, it uses a two-step research design: an elicitation study to identify salient beliefs about a behaviour, followed by the administration of a fixed-item survey to quantify behavioural predictors (Ajzen, 1985). The elicitation study is conducted using personal interviews or focus groups with representatives of a population, in a free-response format (Fishbein \& Ajzen, 2010). The elicitation stage identifies the stakeholders' salient beliefs about attitudinal constructs, subjective norms and perceived behavioural control. These three constructs have been found to be the determinants of intent to perform a behaviour, and in many fields of study intentions have been shown to be strongly predictive of behaviours (Armitage \& Conner, 2001; Kaiser et al., 2005; Fishbein \& Ajzen, 2010; Willcox et al., 2012). The expectation is that by determining the social psychological factors that influence an individual performing a behaviour, one can then change the frequency of the behaviour through targeted outreach programmes.

Our study focuses on the elicitation stage of the theory of planned behaviour, which can yield deep and rich qualitative insights into the target population and is crucial when the goal of the research is to determine appropriate interventions that can be applied to change a behaviour. Through face-to-face interviews a researcher can gain valuable insights and cultural knowledge about a population. As scientists are often not part of the respondent population and do not have extensive knowledge about the social, political and other important cultural aspects of the area, this type of qualitative research is invaluable. It has greater flexibility, attention to context, and can reveal social, political, historical and economic factors that a quantitative study cannot (Sayre, 2004). Compared to quantitative studies, qualitative studies can uncover unanticipated results (Sayre, 2004), and are more internally valid because they are 'better at representing the diversity of the individuals and groups being analysed and examining complex concepts in ambiguous and complex contexts', and researchers who conduct quantitative surveys with large sample populations are often less aware of site-specific cultural differences in their sample population (Drury et al., 2011). Along with the elicitation study questions, we asked respondents to give their views on history, politics and economics, to gain a better understanding of the culture of the area. This information will be used to implement a community-based conservation programme in the area and identify possible barriers to participation by women. By being better informed about the culture of an area, efforts to create a conservation programme may be more likely to succeed (Waylen et al., 2010).

\section{Study area}

As of $201162.7 \%$ of Belize was forested, which is the greatest percentage of forest cover of any country in the Mesoamerican region (ChartsBin, 2011). However, during 1990-2010 it lost $12.2 \%$, c. 193,000 ha, of its forests, mostly as a result of illegal logging (FAO, 2011; Arevalo \& Chan, 2012). The 14,448 ha Vaca Forest Reserve is a protected area within the Chiquibul forest in the Cayo District of western Belize. It was established in 1991 'to maintain adequate stock of renewable natural resources for sustainable use by the local communities and contribute to the national economy' (Manzanero \& Melendez, 2013). The Chiquibul forest along with neighbouring protected areas comprises one of the largest continuous tracts of tropical forest in Central America (Bridgewater et al., 2006). These forested areas are also part of the Chiquibul-Maya Mountains Key Biodiversity Area, which is a priority area for conservation (Arevalo \& Chan, 2012). Despite these designations, as of 2012 a total of almost 6 million board feet $\left(14,158 \mathrm{~m}^{2}\right)$ of lumber have been harvested illegally, damaging 92,316 trees. This has resulted in a loss of almost USD 9.5 million to the economy (Arevalo \& Chan, 2012).

The Cayo District has the largest number of unemployed residents in the country and an unemployment rate of $13.4 \%$, which is $3.3 \%$ higher than the national average (SIB, 2014). The national language of Belize is English; however, our study area is close to the Guatemalan border and many of the local people are bilingual, with some more comfortable speaking Spanish than English. 
There is currently a small community-based conservation group, Friends of the Vaca Forest Reserve, comprising 23 farmers working in the area. There are 21 men and two women in the group, who participate in apiculture, agro-ecological methods of farming (e.g. reforestation), composting and other soil conservation techniques within the reserve borders. Long-term goals of the group include empowering the community to serve as custodians of the natural and cultural resources, poverty reduction, and reforestation (Manzanero \& Melendez, 2013). This access to and sustainable use of the land has given participants a reason to monitor illegal poaching activities and become stewards of the forest. Increasing the presence of people in the forest may reduce illegal activities that are destroying the forest. However, many barriers to community involvement still persist in Vaca, specifically with regard to women. To date, conservation efforts have focused largely on sustainable agriculture, which is generally considered to be a man's job. However, group leaders expressed a desire to encourage greater participation of women in conservation efforts through the creation of a separate programme specifically designed for women (R. Manzanero, pers. comm.).

\section{Methods}

We conducted interviews over a 6-day period in January 2015 in the three communities surrounding the Vaca Forest Reserve: Benque Viejo Del Carmen (population 6,140), San Jose Succotz $(2,322)$ and Arenal (612). The interviews were conducted in accordance with the requirements of the Institutional Review Board of the University of Tennessee (UTK IRB-14-01962-XP). These communities were chosen based on their proximity and accessibility to the Reserve and their potential reliance on forest resources. We conducted 47 semi-structured key-informant interviews with individuals who were knowledgeable about the forest, its resources, the communities or conservation groups. The interviewees included police officers, mayors, educators, religious leaders, current participants in community-based conservation, an NGO leader, resort personnel, women's group leaders, and representatives of government agencies. Women from the general population of each community were also interviewed to elicit responses from the group that will potentially be participating in the communitybased conservation programme. Sampling procedures followed the purposive method, to obtain views and experiences of people who would most likely be affected by, or have special knowledge about, a possible conservation programme (Bernard, 2012; Babbie, 2015). To ascertain the age range of women who might be interested in participating in a community-based conservation programme, we interviewed women of various ages in each community.

Local NGOs and a leading member of Friends of the Vaca Forest Reserve, all of whom are residents of the area, assisted in designing the interview instrument (Supplementary Material). Questions were constructed to identify community and environmental concerns, knowledge of the forest reserve, knowledge of conservation and conservation groups in the area, and ways women could use forest resources sustainably. Additionally, following the elicitation interview format of the theory of planned behaviour (Francis et al., 2004; Fishbein \& Ajzen, 2010), questions were asked to determine respondents' behavioural, normative and control beliefs about women's participation in a conservation programme.

ASK and NCP conducted interviews in English or Spanish, depending on the preference of the interviewee. We collected interviews until saturation was reached (i.e. no new concepts were emerging; Sirakaya-Turk et al., 2011). We recorded the interviews and uploaded them to a computer. Interviews were transcribed into a document by ASK and NCP. The transcripts were open-coded by identifying key words and salient belief statements in each response, and the codes were recorded. Open codes were refined into axial codes of analytical categories and then grouped into common themes. Only responses that were mentioned by at least three respondents were included in our analysis, to give the results credibility according to the triangulation strategy of using multiple sources. This also provides more dependability based on replication logic through the use of multiple locations and groups (Ary et al., 2006).

\section{Results}

A total of 47 interviews were collected, 14 in Spanish and 33 in English (Table 1). Twenty-two women and 25 men were interviewed. Eight interviews were conducted at residences in the small village of Arenal, 11 in the larger village of San Jose Succotz, and 10 in the town of Benque Viejo Del Carmen. The remaining 18 interviews were conducted in the area but at the respondent's place of business: in their office, at the resort or on their farm.

\section{Behavioural beliefs}

The respondents stated seven advantages of participating in a conservation group (Table 2), and responses were grouped into three themes: benefits that a community-based conservation programme would provide for the women involved, benefits for the community, and characteristics of women that would benefit a community-based conservation programme. The most cited advantage was the belief that women would have an influence on others through sharing their passion and knowledge with their family and friends, especially their children. Many respondents stated that women were the centre of the household and the children followed their example. One participant stated: 
TABLE 1 Number of interview participants, based on gender, location of interview, and stakeholder group.

\begin{tabular}{ll}
\hline Characteristic & $\begin{array}{l}\text { No. of participants } \\
(\mathrm{N}=47)\end{array}$ \\
\hline Gender & 22 \\
Female & 25 \\
Male & \\
Location of interview & 8 \\
Arenal & 11 \\
San Jose Succotz & 10 \\
Benque Viejo & 18 \\
Place of business & \\
Stakeholder group & 11 \\
Women & 7 \\
Current participants in community- & \\
based conservation & 6 \\
Teachers & 6 \\
Tourism industry & 3 \\
Government agency & 3 \\
Police & 3 \\
Mayors & 3 \\
Religious leaders & 2 \\
NGO/development groups & 2 \\
Women's group leaders & 1 \\
Private industry &
\end{tabular}

...once a woman has passion for something it is very strong and women play an important role in the aspect of influence, not only with her husband but with her family. A woman is very strong in the house so her word, her passion can be passed on to her kids very easily...

Additionally, some expressed that women's participation would also encourage men to participate.

I think that women are more persuasive. I think that if you have a group, women would be able to persuade the men to get more involved.

The next most frequently mentioned advantage was that women would be able to gain more knowledge about the forest and conservation from participating:

They will learn and they will learn a lot of things, especially taking care of the environment and how to use the resources that the environment offers in order to have a sustainable life or earn some money.

When asked about disadvantages, 15 participants noted that there were no disadvantages of women participating, with lack of time to participate being the next most frequently mentioned response.

\section{Normative beliefs}

When asked who would approve of women's participation in community-based conservation, respondents mentioned the approval of other community groups most frequently. Alternatively, when asked which individuals or groups would disapprove, the majority could not think of anyone, with 20 respondents saying no one would disapprove and nine stating that they did not know. Six respondents said that husbands might disapprove, and three thought that the church might disapprove.

\section{Control beliefs}

Women needing to have an interest or motivation, as well as moral support, were mentioned most often as things that would facilitate their participation:

Willingness specifically. Willingness to be a part of it (the group). I believe that would be the main thing.

I believe, support, moral support, and a constant motivation so that they do not lose track of their objective or goal.

The second most frequently mentioned response was that women would need knowledge about conservation and the programme to participate:

I would say education would be the first thing. Get them to know what is the goal of the group. How they would benefit, what would be the advantages and disadvantages of why they are in that group.

Needing to make an income, needing time to participate, having the materials and needing a place to sell the final product were mentioned less often. When respondents were asked what would make it difficult or impossible to participate, time was mentioned by 15 respondents and was found to be the greatest barrier to participation:

That would be time, because most women who would participate would be women with family and sometimes they don't have the time to come out and do things for the environment.

Not having an interest and having children were also viewed as barriers:

If they wanted to participate I would say the only thing that might keep them back would be family. A lot of people are focused on family so a lot of time I know from my personal experience women tend to leave their personal goals aside and take care of the family, their husband.

\section{Cultural and historical forest use and conservation}

When respondents were asked about the traditional roles of men and women in regard to the forest many believed that traditionally men had extracted wood by logging or firewood collection, farmed, hunted and cleared the forest through slash and burn methods. A few respondents mentioned that some men were involved in forest protection. One respondent expressed the following:

[They] hunt and they grow their milpas (traditional small agricultural plots) in the forest, at the same time they do deforestation and that hurts the forest.

Conversely, many thought that traditionally women had not participated directly in any forest practices but may have assisted their husbands by attending outings to cook for the men or help to harvest crops when needed.

Respondents stated that women would be interested in participating in a conservation group that takes trips into 
TABLE 2 Details of responses regarding behavioural, normative and control beliefs about women's participation in a conservation programme. Not all respondents were asked each question, as some were not local and did not have any knowledge of the local women.

\begin{tabular}{|c|c|c|c|}
\hline Beliefs & Times mentioned ${ }^{*}$ & Beliefs & Times mentioned ${ }^{*}$ \\
\hline Behavioural belief: advantage & $\mathrm{m}=49, \mathrm{n}=43$ & Behavioural belief disadvantage & $\mathrm{m}=49, \mathrm{n}=44$ \\
\hline Benefits to women & 21 & None & 15 \\
\hline Learn more & 13 & Time & 8 \\
\hline Gain an income & 5 & Safety in the forest & 4 \\
\hline Socialize & 3 & Don't know & 4 \\
\hline Benefits to the community & 21 & Need a good leader & 3 \\
\hline Women influence others & 14 & & \\
\hline Help the environment & 7 & & \\
\hline Women's characteristics that would benefit a programme & 13 & & \\
\hline More/better ideas & 4 & & \\
\hline Good planners & 3 & & \\
\hline Normative belief: approve & $\mathrm{m}=47, \mathrm{n}=41$ & Normative belief: disapprove & $\mathrm{m}=43, \mathrm{n}=43$ \\
\hline Community group & 10 & No one & 20 \\
\hline Don't know & 8 & Don't know & 9 \\
\hline Government & 8 & Husbands & 6 \\
\hline Friends for Conservation and Development & 6 & The Church & 3 \\
\hline Most people would approve & 4 & & \\
\hline Control belief: enable & $\mathrm{m}=64, \mathrm{n}=44$ & Control belief: difficult & $\mathrm{m}=64, \mathrm{n}=42$ \\
\hline Women's needs & 48 & Women's barriers & 45 \\
\hline Interest/motivation & 11 & Time & 15 \\
\hline Support & 11 & Children & 9 \\
\hline More knowledge & 9 & No interest & 7 \\
\hline Income & 8 & Money & 5 \\
\hline Time & 6 & Machismo & 4 \\
\hline Group needs & 13 & Need more knowledge & 3 \\
\hline Materials & 5 & Group barriers & 10 \\
\hline Place to sell products & 3 & None & 3 \\
\hline Don't know & 3 & & \\
\hline
\end{tabular}

${ }^{*} \mathrm{~m}$, the total number of times an item in a category was mentioned by a respondent (some respondents mentioned multiple items per category); $\mathrm{n}$, the total number of respondents who answered the question.

the forest but that they were not sure what type of project. However, various types of activities were suggested, such as:

Projects like arts and crafts... where they would actually make something and make a group to where they could make money for themselves and assist themselves financially.

Infrastructure issues, such as drainage, roads and sewage, were mentioned most often when respondents were asked to identify the major issues and concerns in their community. Lack of education and jobs were also mentioned (Table 3):

A lot of the women are not educated. Education is the key. Here, it is very minimal of what it should be. We have a lot of people that left the school at a very young age and there is a lot of teenage pregnancy here, especially in this village. I think they believe that primary school is all that they need. I think that is an issue.

When asked about the environmental concerns in the area, garbage was mentioned most often, and river pollution and drainage were both mentioned in eight of the interviews (Table 3). As drainage problems can cause river pollution, and do in this area, these are closely related:
Definitely, especially during the dry seasons we will have a lot of people that visit the rivers and pollute it. That is a concern because we might not be seeing the effect immediately but I know that all of the animals and the habitat there are being affected.

Overall, 29 respondents were aware of the Vaca Forest Reserve. However, only 18 were able to explain how the forest being designated as a reserve actually protects the area. The benefits that the respondents believed they were getting from the forest reserve were clean air, protection of flora and fauna, and a food source. One respondent also mentioned the benefit of tourism:

Well here especially in Belize yes, here tourism is a big industry so taking care of our forests is very important. People come and see what type of nature we have and if it is not here, people would not be coming and less economy for Belize.

Thirty-nine respondents believed that women would be interested in participating in a conservation programme. Not all respondents were asked the question because some would not have knowledge of the specific culture or the women who would be participating, as they did not live in the area. Only two respondents gave negative responses to 
TABLE 3 Community and environmental concerns mentioned by respondents.

\begin{tabular}{ll}
\hline Concerns & Times mentioned $^{*}$ \\
\hline Community & $(\mathrm{N}=77)$ \\
Infrastructure & 13 \\
Education & 9 \\
Jobs/poverty & 9 \\
Teenage pregnancy & 4 \\
Trafficking/crime & 4 \\
Health & 3 \\
Environment & $(\mathrm{N}=65)$ \\
Garbage & 17 \\
River pollution & 8 \\
Drainage & 8 \\
Pollution & 5 \\
None & 5 \\
Disease & 4 \\
Smoke & 3 \\
\hline
\end{tabular}

${ }^{\star}$ Only responses mentioned at least three times are included. Not all respondents were asked the question, as not all were residing in the study area.

this question. Respondents suggested possible activities, or products that could be harvested by a women's communitybased conservation group, including selling firewood, wood carving, collecting herbs for medicines, collecting seeds for jewellery making, basket weaving, tree planting, and making cahune oil, a traditional cooking oil made from the native cahune nut.

\section{Differences between responses of men and women}

The responses of men and women were analysed separately to identify any differences. Responses to eight questions were found to vary between the sexes (Table 4 ). Women mentioned not having the time to participate as a possible barrier more frequently than men. Some men mentioned that women would need more knowledge to participate but no women expressed this belief. The belief that there are no disadvantages to women's participation was mentioned more often by men than by women. Safety while in the forest was mentioned by some men, but no women considered safety to be an issue.

\section{Discussion}

By conducting qualitative interviews we were able to acquire information about the women and culture in the area that would not have been possible through purely quantitative methods. One of the most important findings was that to pass on information about conservation and its importance, it is necessary to inform women and get them involved. This is not an aspect of women's involvement addressed in most community-based conservation studies, possibly because of the difference in cultures of the study areas (Westermann et al., 2005; Agarwal, 2009). Participants commented that women in these communities have influence on all people, especially within their household, and will be able to transfer information learned in the programme and influence others to participate, thus increasing the outreach and educational reach of the group.

We determined that women in our study area had the greatest familial influence and could pass on what they learned about conservation and the forest to their families, potentially creating a social norm of conservation. This coincides with the idea that women are the matriarchs of the Latin American family and influence many 'social sanctions emanating from the family itself, such as acceptable behaviour (Pescatello, 1973), which can be interpreted as social norms. Women were said to be social and share things with other women, as well as being able to influence men. This was a somewhat unexpected result, given our assumption of the presence of machismo and the resulting low status of women (Cianelli et al., 2008). Conversely, we found that women were the centre of the family, and therefore respected, and should therefore be the origin for instilling conservation beliefs, attitudes and lifestyles. In our study area, involving men exclusively in a community-based conservation programme could potentially achieve some immediate conservation goals but the efforts would eventually diminish if interest is not generated in future generations. Generating interest in future generations could be accomplished through the inclusion of women in conservation efforts. We learned that it is imperative to involve women to disseminate information, generate interest and cultivate a norm for conserving the natural environment.

Regarding disadvantages of participation, male respondents generally believed that there was no disadvantage to women participating in a community-based conservation programme but that women would need more interest and motivation before they would participate; i.e. men think women should participate but they also believe that women may not because they do not have the required knowledge or interest. Women did not express this belief, and maintained they would be able to learn by participating and that learning new ideas motivates their interest. Unlike men, women perceived time to be the biggest barrier to participation. This discrepancy between the views of men and women could indicate that men have an inaccurate perception of women's daily activities. Such discrepancies could prove to be a barrier to starting a women's conservation programme. It will be important during the planning and implementation phase to invite men to informational sessions so that strategies to create more free time for women can be worked out collaboratively.

Men thought that women might be, or feel, less safe in the forest but this was not mentioned by women. Although not widespread, this manifestation of machismo was expressed as women being weak and not safe in the forest. Similarly, it was 
TABLE 4 Differences in the responses of men and women regarding their beliefs about the participation of women in conservation programmes.

\begin{tabular}{|c|c|c|}
\hline \multirow[b]{2}{*}{ Belief } & \multicolumn{2}{|c|}{$\begin{array}{l}\text { Frequency } \\
\text { mentioned }\end{array}$} \\
\hline & Women & Men \\
\hline Not having time would be a barrier to women participating & 13 & 2 \\
\hline Women will learn more by participating & 10 & 3 \\
\hline Not having time to participate is a disadvantage & 7 & 1 \\
\hline Husbands would disapprove of women participating & 6 & 0 \\
\hline There are no disadvantages to participation & 4 & 11 \\
\hline Women would need interest \& willingness to participate & 2 & 9 \\
\hline Women being/feeling safe in the forest is a disadvantage to participating & 0 & 4 \\
\hline Women not having enough knowledge about conservation or the programme would make it difficult to participate & 0 & 3 \\
\hline
\end{tabular}

mentioned a few times by women that their husbands or other men might disapprove of women's participation. This fits with the common definition of machismo as being male domination over women socially (Cianelli et al., 2008), or the idea that women are weak and need to be taken care of by men (Ingoldsby, 1991). Many of the women who said husbands would disapprove of their participation lived in the smallest, most remote village, where it was expressed to us that machismo culture still exists. This may indicate that a transition occurred in the two larger communities, with a move away from machismo to a more progressive, gender equal society. The higher education levels, income and job opportunities for women in the two larger communities are further evidence of this. The relative progressiveness of these two communities is also reflected in their improved infrastructure. Discrepancies among communities aside, most respondents could not think of anyone, even husbands, who would disapprove of women participating, suggesting that a community-based conservation programme designed specifically for women would be accepted in this area.

When planning our research we hypothesized that one of the main benefits of participation would be a means for the women to gain an income. We based our assumption on the idea that people are more likely to change their behaviour if they perceive a positive economic benefit in doing so (Pannell et al., 2006; Corbeels et al., 2014). However, this was not often expressed in the interviews. Rather than needing economic benefits, we found that gaining new knowledge and being able to influence others to practise conservation were important advantages of participating. This is in line with previous research indicating that social benefits are often more important than economic benefits in rural communities in developing areas (Berkes, 2004). Economic initiatives and profit should not be completely excluded, as some participants noted financial gain was an important benefit to participation. Therefore, inclusion of economic benefits in a community-based conservation programme should be considered but should not be the main focus.
Respondents' suggestions regarding possible products to harvest or activities for a women's community-based conservation group were varied. However, there are several barriers that should be addressed if the proposed programme involves the collection of forest products. Participants mentioned time constraints as one of the main barriers to participation, which may be exacerbated if areas where forest products are collected are remote. In an overview of marketing non-timber forest products (NTFP), Belcher \& Schreckenberg (2007) also found distance to collection and marketing sites to be a barrier. The forest collection site as well as the communities themselves are somewhat remote (c. 1 hour's drive), which may make it more difficult to market a product, especially if primary consumers are tourists, as the tourism industry is concentrated on the coast, $>121 \mathrm{~km}$ away. Another barrier we identified, lack of specific market places, is consistent with other research on the difficulties of marketing NTFP in developing countries (Shanley et al., 2002; Belcher \& Schreckenberg, 2007). If the proposed programme is to market NTFP to tourists or local consumers it will be important to analyse the value and supply chains for efficiency and profitability.

A community-based conservation programme could provide some valuable outreach opportunities for the area. We found there was a lack of specific knowledge about the Vaca Forest Reserve and its importance. This could be addressed by a programme that focuses on educating women about conservation issues, specifically in regard to their local forests. In addition to education being a motivating factor for participation, once knowledgeable the women could extend their education through outreach activities focused on local environmental concerns such as river pollution, garbage, drainage issues and smoke pollution. By informing programme participants about the importance of the Reserve and how its ecosystem services mitigate some of these environmental concerns, positive attitudes towards the Reserve could increase, ultimately influencing local communities to become more actively involved in its conservation and management. 
Overall, it appears there is support and a need for a women's community-based conservation programme in communities adjacent to the Reserve. Almost all of the respondents stated that women would want to participate. With the information provided by these interviews we designed a survey and administered it to the women in the area. Using the results of both the interviews and the surveys we will be able to collaborate with the women to design and implement a successful community-based conservation programme that will spread conservation knowledge, empower the women and help conserve the local forest and its resources. These three outcomes will be monitored to help determine the success of the programme, which will be implemented collaboratively by ASK and local women in the area.

Our interviews were integral to identifying desired qualities and underlying conditions that should facilitate the collaborative establishment of a successful women's community-based conservation programme. It is unlikely that some of the key findings (e.g. differences between the responses of men and women regarding the role of women and time constraints on their availability) could have been uncovered through quantitative studies alone. Conservation initiatives that 'ignore traditional values and beliefs are less likely to succeed' (Waylen et al., 2010), and therefore we set out not only to determine what aspects of a community-based conservation programme could make it successful, but to understand the culture, the community and its members.

\section{Acknowledgements}

We thank the WK McClure Scholarship for the Study of World Affairs, and the Rainforest Alliance for financial support. We thank Rafael Manzanero and other staff of Friends for Conservation and Development for their continued support, along with Cayo Women for Conservation and the Program for Tropical Ecology and Conservation Science. We acknowledge Arnoldo Melendez, Hicela Panti and the rest of the Panti family for research assistance. We thank the editors and reviewers for helping to improve this article.

\section{Author contributions}

AK and AW developed the study concept and methodology. NP helped to refine the concept appropriately for the population of interest. AK and NP collected and transcribed the data. AK analysed the data and wrote the manuscript.

\section{References}

AgArWAL, B. (2000) Conceptualising environmental collective action: why gender matters. Cambridge Journal of Economics, 24, 283-310.
Agarwal, B. (2001) Participatory exclusions, community forestry, and gender: an analysis for South Asia and a conceptual framework. World Development, 29, 1623-1648.

Agarwal, B. (2009) Gender and forest conservation: the impact of women's participation in community forest governance. Ecological Economics, 68, 2785-2799.

Ajzen, I. (1985) From Intentions to Actions: A Theory of Planned Behavior. Springer, New York, USA.

Arevalo, B. \& Chan, D. (2012) Mitigating and Controlling Illegal Logging in the Chiquibul Forest. Report to the Forest Department of Belize. Friends for Conservation and Development, San José Succotz, Belize.

Armitage, C. \& Conner, M. (2001) Efficacy of the theory of planned behaviour: a meta-analytic review. British Journal of Social Psychology, 40, 471-499.

Ary, D., Jacobs, L., Razavieh, A. \& Sorensen, C. (2006) Introduction to Research in Education. Wadsworth, Cengage Learning, Belmont, USA.

B A в вIE, E. (2015) The Practice of Social Research. Wadsworth, Cengage Learning, Belmont, USA.

Barrett, C., Brandon, K., Gibson, C. \& Gjertsen, H. (2001) Conserving tropical biodiversity amid weak institutions. BioScience, 51, 497-502.

Belcher, B. \& Schreckenberg, K. (2007) Commercialisation of non-timber forest products: a reality check. Development Policy Review, 25, 355-377.

BERKES, F. (2004) Rethinking community-based conservation. Conservation Biology, 18, 621-630.

Bernard, H. (2012) Social Research Methods: Qualitative and Quantitative Approaches. Sage Publishing, Thousand Oaks, USA.

Bridgewater, S., Harris, D., Whitefoord, C., Monro, A., Penn, M., Sutton, D. et al. (2006) A preliminary checklist of the vascular plants of the Chiquibul Forest, Belize. Edinburgh Journal of Botany, 63, 269-321.

Brown, K. (2002) Innovations for conservation and development. The Geographical Journal, 168, 6-17.

ChartsBin (2011) Proportion of Land Area Covered by Forest. Http:// chartsbin.com/view/2673 [accessed 21 September 2016].

Cianelli, R., Ferrer, L. \& McElmurry, B. (2008) HiV prevention and low-income Chilean women: machismo, marianismo and HIV misconceptions. Culture, Health \& Sexuality, 10, 297-306.

Corbeels, M., de Graaff, J., Ndah, T., Penot, E., Baudron, F., NAUDIN, K. et al. (2014) Understanding the impact and adoption of conservation agriculture in Africa: a multi-scale analysis. Agriculture, Ecosystems \& Environment, 187, 155-170.

Drury, R., Homewood, K. \& Randall, S. (2011) Less is more: the potential of qualitative approaches in conservation research. Animal Conservation, 14, 18-24.

FAO (2011) FAOSTAT. Http://faostat3.fao.org/home/E [accessed 21 September 2016].

Fishiein, M. \& Ajzen, I. (2010) Predicting and Changing Behavior: The Reasoned Action Approach. Taylor \& Francis, New York, USA.

Francis, J., Eccles, M., Johnston, M., Walker, A., Grimshaw, J., Foy, R. et al. (2004) Constructing Questionnaires Based on the Theory of Planned Behaviour. A Manual for Health Services Researchers. Centre for Health Services Research, University of Newcastle upon Tyne, UK.

Getz, W., Fortmann, L., Cumming, D., Du Toit, J., Hilty, J., MARTIN, R. et al. (1999) Sustaining natural and human capital: villagers and scientists. Science, 283, 1855-1856.

Hartup, B. (1994) Community conservation in Belize: demography, resource use, and attitudes of participating landowners. Biological Conservation, 69, 235-241. 
Ingoldsby, B. (1991) The Latin American family: familism vs. machismo. Journal of Comparative Family Studies, 22, 57-62.

Kaiser, F., Húbner, G. \& Bogner, F. (2005) Contrasting the theory of planned behavior with the value-belief-norm model in explaining conservation behavior. Journal of Applied Social Psychology, 35, 2150-2170.

Manzanero, R. \& Melendez, A. (2013) Evolution of a New Management Alternative in the Vaca Forest Reserve. Report for Friends for Conservation and Development, San José Succotz, Belize.

Pannell, D., Marshall, G., Barr, N., Curtis, A., Vanclay, F. \& Wilkinson, R. (2006) Understanding and promoting adoption of conservation practices by rural landholders. Animal Production Science, 46, 1407-1424.

Pescatello, A. (1973) Female and Male in Latin America: Essays. University of Pittsburgh Press, Pittsburg, USA.

Porter-Bolland, L., Ellis, E., Guariguata, M., Ruiz-Mallén, I., Negrete-Yankelevich, S. \& Reyes-García, V. (2012) Community managed forests and forest protected areas: an assessment of their conservation effectiveness across the tropics. Forest Ecology and Management, 268, 6-17.

Prasad Timsina, N. (2003) Promoting social justice and conserving montane forest environments: a case study of Nepal's community forestry programme. The Geographical Journal, 169, 236-242.

Roe, D. (2008) The origins and evolution of the conservation-poverty debate: a review of key literature, events and policy processes. Oryx, $42,491-503$.

SAYRE, N. (2004) Viewpoint: the need for qualitative research to understand ranch management. Rangeland Ecology \& Management, 57, 668-674.

Shanley, P., Pierce, A., Laird, S. \& Guillen, A. (eds) (2002) Tapping the Green Market: Certification and Management of Non-timber Forest Products. Earthscan, London, UK.

SiB (Statistical Institute of Belize) (2014) Annual Report, 2014. Http://www.sib.org.bz/publications/annual-reports [accessed 10 April 2015].
Sirakaya-Turk, E., Uysal, M., Hammitt, W. \& Vaske, J. (eds) (2011) Research Methods for Leisure, Recreation and Tourism. CABI, Wallingford, UK.

Soe, A. \& Sato, N. (2012) Local people's attitudes towards the community forestry: the case studies in the central dry zone of Myanmar. Journal of the Faculty of Agriculture, Kyushu University, 57, 273-280.

Thompson, P. (2013) Sustainability of community-based organizations in Bangladesh. Society \& Natural Resources, 26, 778-794.

Waylen, K., Fischer, A., McGowan, P., Thirgood, S. \& MilnerGULLAND, E.J. (2010) Effect of local cultural context on the success of community-based conservation interventions. Conservation Biology, 24, 1119-1129.

Westermann, O., Ashby, J. \& Pretty, J. (2005) Gender and social capital: the importance of gender differences for the maturity and effectiveness of natural resource management groups. World Development, 33, 1783-1799.

Willcox, A., Giuliano, W. \& Monroe, M. (2012) Predicting cattle rancher wildlife management activities: an application of the theory of planned behavior. Human Dimensions of Wildlife, 17, 159-173.

\section{Biographical sketches}

AMANDA KAESER is interested in studying human attitudes and perceptions about the natural environment and conservation so as to create successful outreach and intervention programmes that can be used to address global environmental issues. ADAM W ILLCOX is interested in explaining stakeholder conservation behaviour by employing social psychology frameworks to address challenges in wildlife management. His research on stakeholder attitudes, norms and other perceptions of natural resources is applied to conservation programming, planning and policy. Nidia Panti's primary interests are to understand the anthropogenic roles and impacts of buffer communities in terrestrial ecosystems and engage in conservation actions that benefit our natural environment. 